\title{
The model of functioning of cargo transportation subsystem
}

\author{
Viktor Korchagin ${ }^{1}$, and Yulia Rizayeva ${ }^{1^{*}}$ \\ ${ }^{1}$ Lipetsk State Technical University, 398600 Lipetsk, Russia
}

\begin{abstract}
Developed the methodology for the organization and control of functioning of cargoes transportation system under real conditions of vehicle operation. The model management system allows you to maintain the biosphere-compatible equilibrium and the balanced interaction of all subsystems. The use of the created system of cargo delivery management taking into account the biosphere-compatible criterion is important and progressive in the created conditions, since it became possible to take into account the criteria when searching for the most economically and ecologically way of delivering goods.
\end{abstract}

\section{Introduction}

Today, the task of the biosphere-compatible development of the scientific, technical, economic activities of man and the processes taking place in the biosphere is acute. Systems with anthropogenic component replace natural ecological systems. Such systems are called socio-nature-economic systems (SNES) - this is part of the techno sphere and the biosphere, limited to a certain territory, where the natural, social and production components and processes are linked by mutually supportive, interacting flows of matter, energy and information [1]. The balance of the natural and production potentials of the territory is reached within the balanced SNES, when natural and anthropogenic objects are interdependent and function as a single whole, interconnected material, energy and information flows (connections) as a result of technological activities.

It is important to achieve such interaction of subsystems when they have the ability to preserve their own opportunities for self-development, while the entire socio-environmental system is functioning optimally and steadily, being self-developing, complex, open. This is achieved through the high development of all elements of the system and their adequate correspondence to each other. Thus, integrity is achieved, which is not reduced to a simple summation of elements.

From the standpoint of a holistic approach to Nature, it is assumed that the integrity of culture is the basic condition for integrity, and as a consequence, a close and well-coordinated relationship of science with ecology, art, philosophy, thus functioning, science will have to move away from the direction only to technical- economic development, which is achieved by the destruction of human life and the natural environment.

* Corresponding author: rizaeva.u.n@yandex.ru 
The integrity of man and Nature is achieved when science comprehends the natural laws of Nature, takes into account its freedom, language, soul, love, striving for joint comprehension. The modern generation does not want to stop reducing the negative impact on the mechanism of the holistic functioning of the biosphere, so the ecological situation developed now threatens of the biosphere.

\section{Material and methods}

The analysis of the available directions of socio-natural-economic of development has led to the conclusion that there is a need for a global transformation of the entire strategy for the development of society. The essence of the strategy is to abandon the uncontrolled influence of human activities on the biosphere, the adoption of rational socio-ecological solutions.

At present, there is an urgent need to ecological the economy. A person must ensure ecological reproduction, because beyond the boundaries of the processes taking place in the environment, cannot talk about the production of material goods and services. For sustainable development of the biosphere, optimal control of man over his evolution, it is necessary to achieve the real unity of mankind $[1,2]$.

At the present time, science needs to solve urgent micro-tasks: find the possible ways for the biosphere to adapt to the conditions that the person creates; to study the possibility of developing new biological characteristics of man to a changing natural environment; and macro-tasks: the study of the regularities occurring in the biosphere, and the use of these results for the integration into the integral system of the natural biosphere and the techno sphere.

In the current conditions of competition in the transport and logistics market, problems constantly arise that require quick resolution. Many of them will be able to solve of the logistics specialist when he will use the theoretical basis of functioning of the socio natural economic transport system.

The effectiveness of the functioning of the socio-nature-economic transport system (SNETS) will be achieved in the event of establishing the relationships of all components of the subsystem. To do this, it is necessary to have a sufficient amount of information that will allow objectively analyzing the factors of external, interior, and natural environments [3]. To solve these problems and all those related to them, we need to move on to the system of the highest order, which examines the mutual influence and mutual relations of the set of components of SNETS. In Fig. 1 shows the systemic representation of SNETS.

The proposed approach identifies research tasks in managing the socio-nature-economic system and control the system in two consecutive actions, which makes it possible to optimally manage the cargo transportation subsystem and, at the same time, to learn about the changes in the delivery of cargo data on the characteristics of cargo transportation subsystem for further improvement of the applied management methods. An important advantage of using the model is the possibility for the system to avoid the negative effects of different elements on each other, since in the proposed scheme the managing impacts on the model must be chosen so, so that they optimally satisfy the necessary trajectories of all outputs. [1]. 


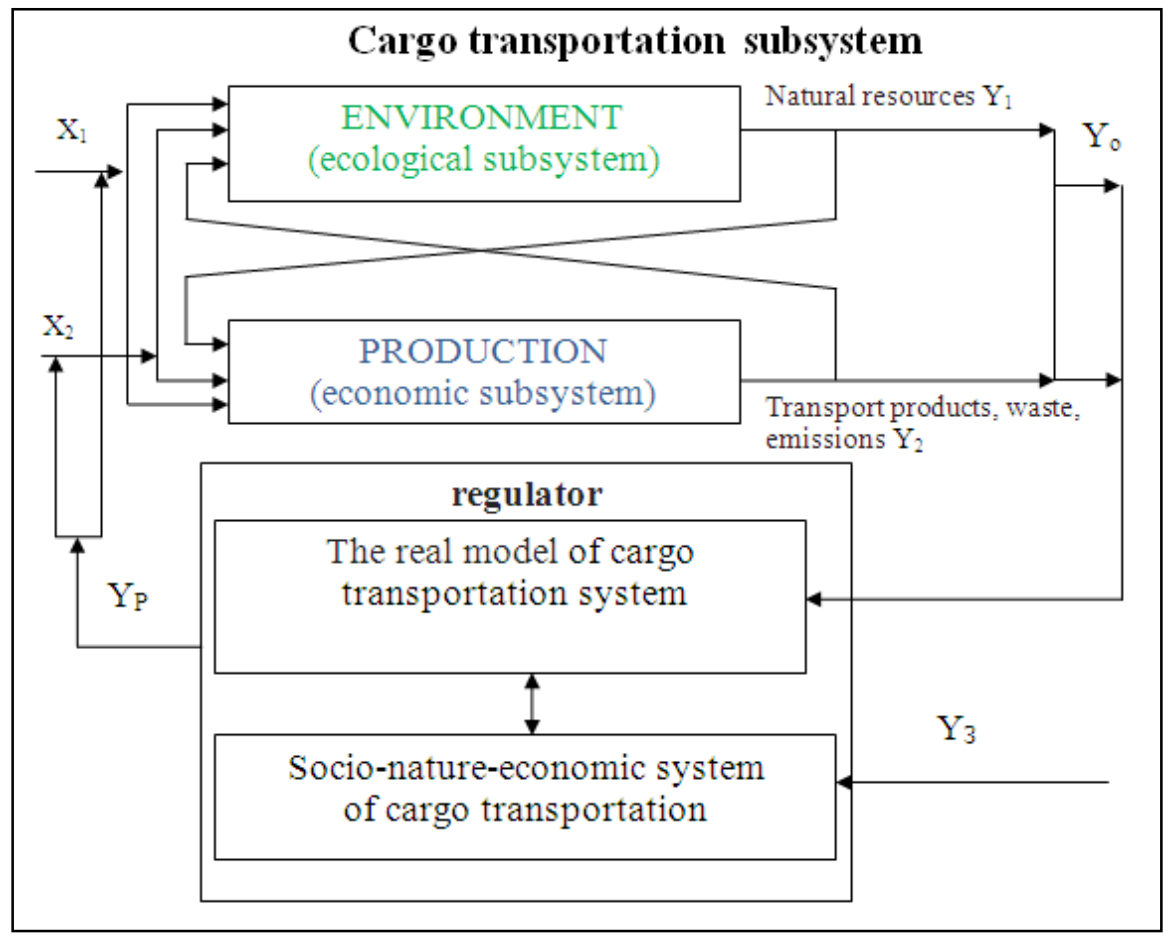

Fig. 1. The model of functioning of cargo transportation subsystem.

\section{Theory}

To reduce the harmful impact of transport on the environment, it is necessary to solve the following main tasks: reduction of harmful emissions into the environment; use of environmentally improved fuels; reduction of energy intensity of transport to the level of indicators of advanced countries; minimization of harmful impact on nature; restoration and replacement of ecological losses and other.

Today not presented scientific tools, based on the criteria of the biosphere compatible management delivery of goods, not developed a common method of managing the process of cargo transportation. To improve the ecological and economic efficiency of cargo transportation management, new scientific methods, principles, means, models and object of research are needed. It is important to develop a scientific basis for planning cargo transportation in an ever-changing environment, taking into account the interests of the environment when making managerial decisions to improve the ecological and economic efficiency of cargo delivery [5].

The developed model of biosphere-compatible management of the cargo transportation system can be formulated in this way: At several points of departure A1, A2, .., An are concentrated a certain number of homogeneous cargoes a1, a2, .., an. This cargo must be delivered to one destination $\mathrm{B}$ with the normative negative impact of the transportation process on the environment and the restriction of the capacity of the procurement station, that is, an equal quantity of cargo must be delivered to each hour interval. The solution of this task will ensure the smooth operation of the points of dispatch, the procurement station, avoid the formation of queues, idle rolling stock, and reduce the negative impact of rolling stock on the state of the environment $[6,7]$. 
The given task can be solved under condition of constant control over work of cars on the line, timely elimination of disruptions in the rolling stock operation, decision-making on stabilization of the ecological situation, if necessary. In this paper, we propose an algorithm for managing the cargo transportation system, which ensures the biosphere-normative functioning of the system (Fig. 1).

The system of cargo transportation includes two subsystems - environment (ecological subsystem) and production (economic subsystem). The peculiarity of its functioning is the following: the output of the ecological subsystem (imported from her natural resources) is the input for the economic subsystem, which transforms the input material and energy flows of natural, external and production resources into the output streams of transport products for the movement of goods and vice versa, the output of the economic subsystem (transport products for the movement of goods, accompanied by emissions of harmful substances into the environment) is the entrance to the ecological subsystem (Fig. 1).

Natural resources imported from the ecological subsystem are necessary for the functioning of the enterprise, its production activities. Some of the objects of the ecological subsystem are necessary as a resource for the economic subsystem; they are used in the production cycle. Part of the natural resources, after passing through several technological stages, is transformed into a transport service. A large part of them again comes to the ecological subsystem, but already in a modified form $[8,9]$.

Management of this system is possible using an automatic regulator, which has predetermined biosphere-normative parameters for the functioning of the SNES. The regulator simulates a real model of the cargo transportation system, compares it with the model of the operation of the SNES, determines and gives the optimal input effects of YP for the ecological and economic subsystems $\mathrm{X} 1$ and $\mathrm{X} 2$, takes into account the output characteristics of the subsystems Y1 and Y2 and, thus, provides a biosphere-compatible mode of the cargo transportation system [10].

As a result of using the proposed mechanism for managing the cargo transportation system when subsystems interact using a regulator with pledges biosphere-compatible parameters, it is possible to optimize the input and output impacts for the ecological and economic subsystems, which will ensure a biosphere-compatible mode of operation of the system as a whole $[11,12]$.

\section{Conclusion}

The use of the results of the model allows us to search for effective solutions to the problems of reconciling the ecological and economic interests of society and on improving the maintenance of equilibrium and the balance of interaction of all subsystems.

On the basis of the biosphere-compatible criterion [10], a model of the cargo delivery management system has been developed, which allows to achieve: environmentally improved and efficient cargo transportation system in the region; support the balanced interaction of all subsystems SNES [11,13].

The use of the created system of cargo delivery management taking into account the biosphere-compatible criterion is important and progressive in the created conditions, since it became possible to take into account the criteria when searching for the most economically and ecologically way of delivering goods: minimization of resource-consuming materials for delivery and resource-intensive production; optimization of the level of ecological and economic efficiency and ecologization of production [14].

In conditions of globalization and the need to use energy and resource-efficient technologies in the transport sector, socially-oriented sectors of the economy acquire a strategic character, which requires socially responsible business in accordance with the principles of sustainable development. The organization of efficient transportation in the city, 
taking into account the requirements of ecological management and energy management, allows to optimize the use of material and fuel and energy resources and reduce the total costs for the delivery of goods.

The reported study supported by the Russian Science Foundation within the project 18-71-10034.

\section{References}

1. V.A. Korchagin, Yu.N Rizaeva, Noospheric approaches to the creation of socioenvironmental transport and logistics systems, Motor Transport Enterprise, 1, pp. 45 48 (2012)

2. A. Novikov, I. Novikov, A. Katunin, A. Shevtsova, Adaptation Capacity of the Traffic Lights Control System (TSCS) as to Changing Parameters of Traffic Flows Within Intellectual Transport Systems (ITS), Transportation Research Procedia, 20, pp. 455 462 (2017)

3. V.A. Korchagin, A.N. Novikov., Yu.N. Rizaeva, Construction of a synchronized and efficient logistics supply chain, The world of transport and technological machines, $\mathbf{4}$, pp. 139-142 (2014)

4. V.A. Korchagin, Yu.N. Rizaeva, T.V. Korchagina, Scientific-based management of open road transport systems, Fundamental research, 11, pp. 148 - 152 (2012)

5. N. Danilina, D. Elistratov, Organization of Municipal Transport Access Control System. Passenger Service Models, Transportation Research Procedia, 20, P. 132-137 (2017)

6. V. Boschian, P. Paganelli, Business Models for Advanced ICT in Logistics, In: Lu M., De Bock J., editors. Sustainable Logistics and Supply Chains. Contributions to Management Science. Cham: Springer. pp.15-51 (2016)

7. A. Asaul, I. Malygin, V. Komashinskiy, The project of intellectual multimodal transport system, Transportation Research Procedia, pp. 25-30 (2017)

8. S.G. Yemel'yanov, Ye.V. Bruma, To the calculation of the parameter of the biosphere compatibility of the urbanized territory, Biosphere compatibility: human, regions, technology, 3, pp. 3-11 (2013)

9. A.N. Novikov, A.A. Katunin, A.N Semkin, Modern Approaches to the Management of the Transport of Goods by Road Transport. The world of transport and technological machines, 1 (48), pp. 119-126. (2015)

10. V.A. Korchagin, L.P. Stankevich, A.A. Tursunov, Yu.N. Rizaeva, Environmental safety of socio-economic transport systems in the light of integrity. Bulletin of TTU, Dushanbe, 2, pp. 155-160 (2013)

11. P. Przhibyl, A.N. Novikov, O. Przhibyl, Associated systems and transport telematics. The world of transport and technological machines, 2 (49), pp. 96-102 (2015)

12. E. Semchugova, V. Zyryanov, N. Negrov, A. Nikitina, Models of estimation of passenger service Quality, Transportation Research Procedia, 20, pp. 584-590 (2017)

13. A. Novikov, I. Novikov, A. Katunin, A. Shevtsova, Research of influence of dynamic characteristics for options controlled intersection, Procedia Engineering, 187, pp. 664 - 671 (2017)

14. V.A. Korchagin, A.N. Novikov, S.A. Lyapin, Yu.N. Rizayeva, Complex self-developin transport systems, International journal of pharmacy and technology. Vol. 8, Issue No.3. pp. $15253-15261$ (2016) 